\title{
Marginación en la ciudad
}

Una legítima aspiración de lograr la plenitud humana, la seguridad vital, la autoatirmación personal, el deseo de reconocimiento por parte de los otros, es sólo objetivo de algunos y no resulta accesible para los más marginales.

\section{Por Maria Pilar LORENTE*}

Salir a la calle en una gran ciudad - Madrid, por ejemplo- es ser testigo de escenas que se repiten en lugares estratégicos: los semáforos se convierten en puntos de venta de pañuelos, bayetas y otros articulos de escaso valor comercial, cuando no de oferta casi obligada de limpieza del parabrisas del automóvil, mediante una propina improvisada; las puertas de los templos se ven rodeadas de grupos de mendigos que acosan a los fieles a la entrada y salida, aprovechando los ratos libres para negociar su puesto en ese lugar, a cambio de ciertas contra-prestaciones económicas; en calles de mucho tráfico peatonal, a la puerta de grandes almacenes o importantes cafeterias, se encuentran con frecuencias grupos familiares, con niños somnolientos arrebujados entre mantas viejas, que han colocado el biberón del más pequeño como reclamo y con carteles de dificil caligrafia que presentan patéticos mensajes para llamar la atención de los viandantes y solicitar una ayuda económica; los vagones del Metro son muchas veces escenario de niños o adultos que, con tono lastimero, expresan su angustiosa situación, a la vez que afirman su ética personal con el convencimiento de que "más vale pedir que robar", para recabar después la generosidad de los viajeros presentando curiosos recipientes donde recoger algunas monedas.

Estas y otras escenas semejantes, que parecian impensables en otras etapas de nuestra historia, se multiplican ahora en progresión preocupante. Pero, ¿qué hay realmente detrás de estos hechos? ¿Se hacen asi patentes determinadas situaciones de marginación socioeconómica verdadera? ¿Tiene que ver todo ello con el complejo mundo de la pobreza? ¿Estarán relacionados con el acuciante problema

\footnotetext{
* Licenciada en Sociologia. Asistente social.
} 


\section{Pilar Lorente}

del paro laboral? ¿Sera la dinamıca misma del fenómeno urbano quien va generando formas diversas de marginación en determinadas personas y colectivos?

Lo clerto es que este hecho resulta paradójico en un pais como el nuestro, en el que los niveles de vida se han elevado notoriamente en las últimas décadas, la renta per cápita aumenta progresivamente, sobre todo en grandes ciudades, los indices de consumo se incrementan de forma importante, el P.I.B. experimenta un crecimiento real. $Y$ en este mundo de incoherencias y desigualdades se encuentran muchas personas y grupos humanos, que tienen que subsistir a pe sar de las limitaciones que les colocan en estado de inferioridad con respecto a sus semejantes "normales", en un mundo "aparte". Situaciones de extrema necesidad, de graves carencias, de pobreza y miseria, asentadas en lugares estratégicos de grandes ciudades, que afectan a niños sin poder acceder regularmente a la educación, a trabajadores en paro prolongado, ancianos con pensiones infimas, grupos que sufren presiones por su improductividad, o por su etnia u otras causas sociales, politicas, etc.

La referencia se suele hacer hacia la estructura socio-económica, que resulta enormemente desigual e injusta, fruto de un sistema económico que genera posibilidades distintas para unos u otros, donde el valor producción sigue siendo prioritario $y$, como consecuencia, los no productores o no consumidores, que no generan capital, van quedando al margen de los más influyentes.

Marginación y pobreza. Dos conceptos, dos fenómenos, dos hechos sociales, que confluyen con demasiada frecuencia en una misma realidad para muchos conciudadanos, sin que la mayoria lo cosidere asignatura pendiente de nuestra convivencia social.

La presente reflexión se orienta fundamentalmente al análisis conceptual, sin entrar en el estudio empirico de aquellas situaciones marginales que observamos cada dia.

\section{EL FENOMENO SOCIAL DE LA MARGINACION}

El concepto de marginación es tan complejo como el conjunto de problemáticas que comprende, y controvertido según el punto de vista desde el que se contemple: o el camino de llegada que se considere resulta determinante, o la realidad existencial de quienes la sufren. De hecho, en toda sociedad hay slempre individuos que viven "al margen" de la dinámica social. 


\section{Marginación en la ciudad}

Pero no es lo mismo ser marginados en la sociedad, que marginados por la sociedad. Es decir, que algunos se situan ahi voluntaria y activamente, optando por no asumir ninguna forma de participación, tal vez como alternativa a determinados mecanismos del conjunto social con los que no están de acuerdo; es el caso de ciertos movimien. tos y grupos contra-culturales, en su mayoria organizados en torno a objetivos. Otras personas o colectivos se ven abocados involuntariamente, por causa de complejos procesos, a vivir situaciones marginales, generalmente vinculadas a estados de carencia y necesidad grave. Estos son los que comunmente se llaman "marginados", que no forman grupo social con caracteristicas propias, sino que suelen vivir pasivamente condiciones de exclusión social, de tipo más bien estructural, con respecto al conjunto social. Son colectivos muy diversos, que ofrecen toda una gama de realidades marginales distintas, de diversas características y etiologías: enfermos crónicos, anclanos, parados, presos y ex-presos, madres solteras, niños en riesgo o con graves carencias, mendigos, vagabundos, minorias étnicas...

Hoy el concepto de marginacion viene más bien marcado por la reacción social ante el fenómeno. Para unos, lo esencial son las consecuencias de la no-participación, ya sea de forma activa o pasiva. Se trata de no tomar parte en la vida y estructuras comunes, aunque lo que en muchos casos falte es la oportunidad y el derecho a tal participación. Otro elemento se refiere a la idea de no tener acceso en un nivel medio equiparable de calidad de vida, entendiendo además que este tener acceso supone, no sólo capacidades personales y posibilidades de promoverlas, sino también los niveles de información necesarios para actuar conscientemente; y junto a ello, que la calidad de vida, con criterios de dignidad aceptable, implique poder contar con un mínimo de bienes y recursos. La marginalidad se suele definir también por referencia negativa al concepło de integración, la cual implica relación con la pluralidad de un conjunto, es decir, cumplimiento de normas comunes, aceptación de ideas y valores sociales, consenso sobre la utilización de medios, distribución adecuada de tareas.

Todas estas diversidades conceptuales no esclarecen, sin embargo, la principal cuestion que es previa a todo discurso y que tiene dificil respuesta: Dónde se sitúa la línea divisoria entre lo normal o lo marginal, quiénes son los sujetos que lo definen y con qué criterios, qué procesos sociales tacilitan la marginalidad estructural, cuáles son los elementos definitorios de la condición marginal. 


\section{Ma Pilar Lorente}

\section{Cuadro n: 1}

\section{MARGINADOS}

\begin{tabular}{|c|c|c|c|}
\hline & PARTICIPACION & ACCESO & INTEGPACION \\
\hline 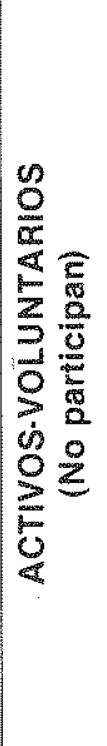 & $\begin{array}{l}\text { No toman parte } \\
\text { en la dinámica } \\
\text { social. } \\
\text { Comportamiento } \\
\text { desviado respec- } \\
\text { to a normas y va- } \\
\text { lores. }\end{array}$ & $\begin{array}{l}\text { Optan por otra al- } \\
\text { ternativa social. } \\
\text { Refuerzan sus } \\
\text { modos de vida } \\
\text { autónomos. }\end{array}$ & $\begin{array}{l}\text { Aislamiento vo- } \\
\text { luntario } \\
\text { No aceptan la } \\
\text { pluralidad del } \\
\text { conjunto: ideas, } \\
\text { valores, utiliza- } \\
\text { ción de medios. } \\
\text { No asumen nor- } \\
\text { mas, responsabi- } \\
\text { lidades ni distr- } \\
\text { bución de tareas. } \\
\text { Inadaptación, } \\
\text { con repercusio- } \\
\text { nes sociológicas. } \\
\text { Desarraigo volun- } \\
\text { tario. }\end{array}$ \\
\hline 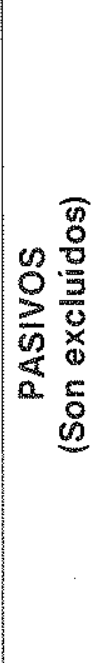 & $\begin{array}{l}\text { No tienen oportu- } \\
\text { nidad ni derecho } \\
\text { a participar. } \\
\text { Comportamiento } \\
\text { desviado sin me- } \\
\text { dios de ajuste. } \\
\text { No tienen autono- } \\
\text { mia para vivir por } \\
\text { sí mismos. }\end{array}$ & $\begin{array}{l}\text { Exclusión social } \\
\text { estructural. } \\
\text { No cuentan con } \\
\text { un mínimo de bie- } \\
\text { nes y recursos. } \\
\text { Faltan medios pa- } \\
\text { ra nivel de vida } \\
\text { aceptable. } \\
\text { Carencia de bie- } \\
\text { nes socialmente } \\
\text { valorados. } \\
\text { Sin posibilidad de } \\
\text { promoción de ca- } \\
\text { pacidades. }\end{array}$ & $\begin{array}{l}\text { Inadaptación y } \\
\text { desarraigo hasta } \\
\text { grados extremos. } \\
\text { Carecen de po- } \\
\text { der. } \\
\text { Rechazo Social. } \\
\text { Sin medios de in- } \\
\text { formación para } \\
\text { actuar conscien } \\
\text { temente. }\end{array}$ \\
\hline
\end{tabular}


Marginación en la ciudad

\section{Factores que generan marginación social}

Si nos referimos al concepto común de marginación, es decir, la que resulta de los diversos mecanismos de exclusión, es evidente que no se pueden determinar con exactitud los complejos procesos por los que se produce la degradación individual y social, que conduce a muchos a situaciones marginales con respecto al conjunto. No es posible establecer una correcta y sistemática relación de causaefecto, pero los estudiosos señalan algunos elementos que resultan desencadenantes, según su peculiar concepción y punto de vista.

Entre los rasgos estructurales de la sociedad actual, que analiza Garcia Roca (1), parece que la complejidad y la conflictividad son as. pectos que configuran decisivamente toda la realidad social, las cuales hacen posible las grandes diferencias y desigualdades. Este mismo autor acentua las distancias que hoy se dan entre lo que él llama el mundo integrado y el mundo de la marginalidad. Los "integrados" serian - en su opinión - los que tienen trabajo, cuentan con medios de alimentarse dignamente, tienen acceso a comunicarse, pueden valerse por sí mismos en las diversas situaciones. Los "marginales", por el contrario, forman un mundo compuesto por los sin-trabajo, los que carecen de saber y de poder, los que no pueden sentirse autónomos para solucionar sus propios riesgos, los que están privados de la comunicación.

Una concepción un tanto tradicional, aunque hoy se utilice por ciertas conveniencias, distingue factores personales o endogenos, a diferencia de los ambientales o exógenos. Los primeros, los personales, son aquéllos que se sitúan en el individuo, circunstancias personales que desencadenan situaciones negativas. Seria el caso de los enfermos crónicos, disminuidos físicos con taras a incapacidades permanentes, afectados por graves patologias psiquicas, con anomalias sexuales importantes; condicionantes que provocan graves dificultades para el trabajo y las relaciones sociales ordinarias, 0 que generan un desvío de la conducta estándar o incluso de peligrosidad social. Los factores exógenos o ambientales se encuentran en el contexto social y operan de forma excluyente sobre la persona: conflicto y desintegración familiar, desempleo, factores culturales y educativos que provocan desigualdades, aspectos sociales de prejuicios o discriminaciones, condicionantes políticos.

El gran dilema se situa, sin duda, en el modelo ideológico de hombre y de sociedad que se nos impone. El ideal humano del bien-estar y del bien-vivir, inducido por un tipo de desarrollo que prima la competitividad y el dinero, fomenta mecanismos de ansiedad y frustración, 


\section{Ma Pilar Lorente}

individuales y colectivos. Es crisis que afecta a las personas y a la sociedad en general, a la que se une la no menos importante crisis de valores, produciendo resquebrajamientos decisivos en la vida social. En este modelo de sociedad, resulta enormemente peligroso definir y situar el fenómeno de la marginación, si no es rompiendo mitos trasnochados y desviados. Hoy resulta inadmisible generalizar el concepto, con parámetros tradicionales, pero falta aún mayor sensibilización en la conciencia colectiva para comprender y asumir en su autentica dimensión la realidad sociológica de este fenómeno de nuestra sociedad.

\section{La pobreza que margina}

Los términos marginación y pobreza incluyen prácticamente la misma realidad, salvo en determinados casos de exclusión voluntaria. En general, se conciben como dos apariencias de un mismo fenómeno, que incluye dependencia y carencias, y que en definitiva lleva a la exclusion social.

\section{Cuadro n: 2}

\begin{tabular}{|c|c|}
\hline INTEGRADOS & MARGINADOS \\
\hline - Tienen trabajo & - Sin trabajo \\
\hline $\begin{array}{l}\text { Tienen trabajo de subsis. } \\
\text { tencia digna }\end{array}$ & $\begin{array}{l}\text { - Graves carencias de bienes } \\
\text { fundamentales }\end{array}$ \\
\hline $\begin{array}{l}\text { Posibilidades de comunica- } \\
\text { ción con los demás }\end{array}$ & $\begin{array}{l}\text { - Privados de la comunica- } \\
\text { ción }\end{array}$ \\
\hline \multirow[t]{2}{*}{$\begin{array}{l}\text { - Acceso a la educación, a la } \\
\text { información y al poder }\end{array}$} & $\begin{array}{l}\text { - Carecen de saber y de po- } \\
\text { der }\end{array}$ \\
\hline & $\begin{array}{l}\text { - Sin oportunidad ni derecho } \\
\text { a participar } \\
\text { - Rechazo o presión social } \\
\text { que crea frustraciones }\end{array}$ \\
\hline $\begin{array}{l}\text { Posibilidad de adquirir nue } \\
\text { vas capacidades }\end{array}$ & $\begin{array}{l}\text { - Sin medios de promoción } \\
\text { integral }\end{array}$ \\
\hline $\begin{array}{l}\text { Proyecto de vida relativa- } \\
\text { mente estable }\end{array}$ & $\begin{array}{l}\text { No autónomos para solu- } \\
\text { cionar sus riesgos }\end{array}$ \\
\hline
\end{tabular}




\section{Marginación en la ciudad}

La pobreza ha sido entendida tradicionalmente como una realidad de todos los tiempos, aunque la consideración de pobre no siempre ha sido igual. La historia nos habla de pobres como lacra social, o gentes en situación patológica, o más recientemente como protagonistas de un hecho cultural.

El concepto de pobreza hace siempre relación a un estado de escasez, de carencia de lo necesario para el sustento vital. Desde la perspectiva de las ciencias sociales, pobreza es "aquella situación en la que se produce una carencia notable de bienes socialmente valorados y escasos por debajo de un nivel de vida que se considera inaceptable" (2).

En consecuencia con esta definición, el concepto sociológico de pobreza resulta siempre relativo según los contextos en los que se produce. Un estado de carencia y de necesidad es distinto en una u otra sociedad, las cuales cuentan con sus peculiares sistemas de normas y valores capaces de diferenciar la condición de pobre respecto a la del resto de esa sociedad. No es lo mismo ser pobre - o ser ricoen un pais desarrollado y con alta renta per cápita, que esto mismo en paises en vias de desarrollo o en los del denominado tercer mundo.

En un estudio sociológico publicado por Cáritas Española, cuyo titulo es "Pobreza y marginación" (3), suficientemente conocido, valorado y hasta criticado, se habla de la existencla de ocho millones de pobres en España, tomando como referencia el llamado "umbral de pobreza". Este término utiliza el mismo indicador que el Informe Roland Boyles sobre la pobreza en la CEE 1983, y está cifrado en la mitad del ingreso medio per cápita, que para el año 1984 suponia 12.647 Ptas./mes.

Las necesidades y carencias a que se refiere el concepto de pobreza son múltiples y de diverso contenido. Es decir, que hay diferencias en las formas de ser pobre, las cuales se pueden localizar al menos en tres aspectos fundamentales: por su jerarquización (4), (primarias, vitales, y secundarias o de autorrealización); por su contexto (fundamentales, o accesorias según el status social); por su cualidad (económicas, psicológicas, sociales).

Es evidente que los conceptos de pobreza y marginación hacen referencia a realidades que se identifican prácticamente. En nuestra sociedad insolidaria y desigual, la marginación estructural se nutre con mecanismos diferenciantes, como el paro, las carencias fundamentales, la pobreza en general. Frente a las necesidades individuales, incluso las más fundamentales, se encuentran múltiples estrategias de exclusión social, con el objetivo de mantener el sistema institu- 


\section{Pilat Lorente}

cional. Pobreza marginada y marginación con pobreza son dos realidades que se alimentan mutuamente en una peculiar dinámica que resulta ser funcional a ciertas estructuras sociales.

\section{Formas de marginacion social}

La compleijad de los procesos de llegada a los estados de marginación social, hace dificil su caracterización y clasificación tipológica.

Entre las caracteristicas comunes, tradicionalmente consideradas, se pueden señalar algunas: a) Comportamiento desviado con respecto a las normas y valores de la sociedad, en sus dos vertientes: la que considera que el individuo no se ajusta a las normas, o la acción excluyente de la sociedad que rechaza al individuo y no le ofrece los medios para ese posible ajuste. b) Inadaptación social, es decir, ruptura entre los valores de la sociedad dominante y las formas de vida de los considerados "aparte"; inadaptación entendida desde diversas perspectivas o con repercusiones diversas (juridica, sociológica, asistencial), con un importante componente psicológico. c) Desarraigo, en el sentido de desvinculación de la red de estruciuras sociales; son los carentes de responsabilidad y obligaciones reciprocas, sin posición social definida, que se procuran formas simples de ayuda. El grado extremo de estos desarraigos serian los vagabundos y transeuntes habituales, refractarios a toda vinculación laboral y social estable.

Construir una tipologia de la marginación supondria tanto como poder clasificar en distintas categorias los rasgos comunes que identifican las diversas y complejas situaciones consideradas marginales. La dificultad está en la concepción que subyace a cada concepto, en el punto de vista desde el que se categoriza cada una de las realida. des marginales.

Una sencilla clasificación, no elaborada desde teorias cientificas, pero que quizá resulte válida, es la que a continuación presento, aunque con ciertas cautelas dado que cada uno de los conceptos precisaria una explicación más detenida. Se trata de tomar algunos aspectos que resultan destacables y que distinguen unas situaciones de otras, aunque todos ellos se encuentran naturalmente interrelacionados.

a) Por el tiempo en que tienen lugar

1. Los que llegan a la marginación (momentos de crisis)

2. Los que nacen en ella (etiología familiar o social) 


\section{Marginación en la ciudad}

b) Por su manifestación social

1. Como situación impuesta y simplemente sufrida.

2. Como conducta que reacciona ante la imposición.

3. Como alternativa, buscada y reivindicada, ante la crisis de valores.

c) Por su origen social

1. Desarraigados (sentimiento de no-pertenencia).

2. Ancianos (procesos diversos de segregación).

3. Minusválidos físicos y psíquicos (en función de su no "productividad" social).

4. Parados, tanto adultos como jóvenes.

5. Gitanos (raiz étnica y cultural).

d) Por sulocalización

1. Urbana (formas de exclusión en grandes concentraciones)

2. Rural (zonas geográficas deprimidas)

e) Por su razón explicativa

1. Alternativa (auto-exclusion activa frente a la presión social; movimientos contra-culturales)

2. Evasiva (solución ante la imposición normativa de la organización institucional)

3. Natural, de exclusión (parte de convencionalismos, que no admiten participación)

4. Artificial (factores ambientales o estereotipos que condicionan).

5. Cultural (por modelos culturales que impiden la convivencia; gitanos...)

6. Justificativa (justificación legal frente a conductas tipificadas como penalizables; delincuencia, prostitución.

\section{A modo de sintesis}

Hablar hoy de un tema, tan antiguo y tan actual, como el de la mar. ginación social, resulta tarea dificil y arriesgada. ¿Qué se puede decir del complejo mundo de la pobreza y la marginación en nuestra sociedad? Habria que determinar con precisión quiénes son y dónde están los verdaderos pobres de hoy, qué clase de carencias les caracterizan, cuáles son los elementos diferenciadores por los que se sien. ten realmente al margen.

El punto crucial son las enormes desigualdades sociales de todos los tiempos. Desigualdad que se produce, no sólo por un reparto injusto de los bienes y recursos, sino muy especialmente por un siste- 


\section{Ma Pilar Lorente}

ma estructural que impide el acceso igualitario de todos, marcando diferencias y excluyendo a algunos de aquello que es comun. Lo que resulta verdaderamente preocupante no es tanto que la pobreza sea un signo de diferenciación social, sino sobre todo que la desigualdad sea la que cause pobreza y marginación. O lo que es lo mismo, que a costa de los más pobres, los ricos puedan hacerse más ricos.

Sorprende que los mecanismos de acaparamiento injusto y de competitividad insolidaria, se produzcan en un momento en que pare. ce se va despertando en algunos la conciencia del "ser" contra el "tener", encarnada en movimientos de recuperación del Yo. Una legitima aspiración de lograr la plenitud humana, la seguridad vital, la autoafirmación persomal, el deseo de reconocimiento por parte de los otros, es sólo objetivo de algunos y no resulta accésible para los más marginales.

Esta enorme distancia entre las necesidades individuales, que se hacen sociales, y los procesos de insolidaridad e injusticia, crea más frustraciones que proyectos atiemativos. Será necesario tomar en cuenta este reto y obrar en consecuencia.

\section{BIBLIOGRAFIA}

CASADO, D. "Por una acción social y cultural alternativa". F. C. P. n. 50 . Marsiega. Madrid, 1984

COMUNIDAD DE MADRID. Instituto Regional de Estudios, "Marginación Social". Madrid, 1985.

GARCIA VARCARCEL., J. y otros. "La pobreza en España y sus Causas". Fundación Agape. Madrid, 1984.

PARLAMENTO EUROPEO. "Informe Roland Boyles sobre la pobre en la C.E.E., $1983^{\prime \prime}$

REVISTA "DOCUMENTACION SOCIAL". Cáritas Española. Madrid. Algunos números de interes.

- 28. - "Sociedad y marginación". Julio-septiembre, 1977.

- 44.- "Marginación social en España". Jullo septlembre. 1981.

-56-57.-." "Pobreza y mafginación". Jutio-diciembre, 1984.

- 59,-m "Menores marginados". Abril-iunio, 1985.

- 60-61.- "Transeuntes y Albergues". Julio-diciembre, 1981

- 64.- "Los Servicios Sociates". Julio-septiembre, 1986.

- 69.- "Metodologia para el Trabajo Soclal". Ootubre-diciembre, 1987.

SAMPEDRO, J.L. "Conciencia del subdesarrollo". Salvat. Barcelona, 1982.

VALENTINE CH. "La cultura de la pobreza", Amorrortu. Buenos Aires, 1972

VARIOS. "Estudio sobre la problemática social y humana de Madrid". Cáriłas Diocesana. Madrid, 1980

VARIOS. "Los pobres en las sociedades ricas". Sal Terrae, Santander, 1974 